\title{
Importância da Comunicação Organizacional na Atuação das Equipes de uma Instituição de Ensino Superior na Cidade de Juazeiro do Norte - CE
}

\author{
Islly Gabrielle Tavares Limachi ${ }^{1}$; Marysângela de Oliveira Tavares ${ }^{2}$
}

Resumo: Este artigo trata do tema comunicação organizacional, que tem como objetivo geral analisar a percepção dos colaboradores quanto ao processo de comunicação organizacional de uma IES- Instituição de Ensino Superior na cidade de Juazeiro do Norte - CE. O assunto comunicação organizacional é algo bastante discutido no mundo organizacional e na academia, pois, é de fundamental importância para o andamento e desenvolvimento de toda e qualquer empresa,que busca executar processos de forma eficiente e eficaz. Para tanto, primeiro foi feita uma revisão bibliográfica sobre o tema estudado, em seguida uma pesquisa quantitativa com os diversos setores da Instituição, com a aplicação de um questionário. Nele se obteve as respostas pretendidas pela pesquisa. Nos resultados, foram apontadas as ferramentas consideradas mais importantes pelos colaboradores, verificando uma diferença sobre as que eles têm conhecimento que a faculdade utiliza. Também foi detectado que a maioria considera boa a comunicação da IES, mas que pode ser melhorada pelo aumento e melhoria dos seus recursos tecnológicos.

Palavras-chave: Comunicação Organizacional, Interna, Canais comunicação.

\section{The Importance of Organizational Communication in the Team Performance at an Higher Education Institution in the City of Juazeiro do Norte-CE}

\begin{abstract}
This article deals with the subject internal organizational communication, which aims at analyzing the perceptions of employees regarding the process of organizational communication in a HEI - Higher Education Institution in the city of Juazeiro do Norte - CE. The subject of organizational communication is something often discussed in the organizational world and in academia, then, is of fundamental importance for the progress and development of any enterprise that seeks to perform processes efficiently and effectively. For this, first a literature review on the subject studied, then a quantitative research with the various sectors of the institution, with the application of a questionnaire. In which it was obtained the required responses to the survey. The results were cited the tools considered most important by employees, checking on a difference that they are aware that the college uses. It was also found that the majority considers good communication of the HEI, but can be improved by increasing and improving their technological resources.
\end{abstract}

Keywords: Organizational Communication, Internal Communication, Communication channels.

\footnotetext{
${ }^{1}$ Graduação em Administração pela Faculdade Paraíso do Ceará (2011). Atualmente é professora de administração da Faculdade Latino Americana de Educação. Contato: nenita2011@ @otmail.com;

${ }^{2}$ Graduação em Administração pela Faculdade Paraíso do Ceará (2011), graduação em Geografia pela Faculdade de Formação de Professores de Serra Talhada e Especialização em Geografia e Meio Am pela Universidade Regional do Cariri. Contato: tavaresmarysangela@ gmail.com.
} 


\section{Introdução}

O público interno das organizações nunca foi tão valorizado como atualmente. As empresas começaram a enxergar seus recursos humanos como um diferencial frente ao mercado. E nada melhor como valorizar seus recursos, como investir, analisando e identificandoseus pontos fracos e fortes. A partirdaí foidada a importância necessária a comunicação organizacional, contribuindo para a integração de toda a empresa, refletindo nos seus públicos internos e externos.

Todas as pesquisas feitas na área de comunicação têm extrema importância, porque atingem a empresa internamente, interferindo nos processos e nos métodos utilizados, para o alcance de seus objetivos. Com isso a comunicação torna-se grande influenciadora no resultado final das atividades da organização. $\mathrm{O}$ desempenho da organização como um todo só tem a melhorar e se fortalecer. Matos (2006) ressalta que a comunicação interna é a ferramenta que a administração utiliza para compartilhar com os seus funcionários a missão, valores, objetivos e metas da empresa. Através dela, é que a empresa irá orientar desenvolver, motivar e integrar as pessoas.

Uma comunicação eficaz tornou-se indispensável para todos os tipos de empresas, inclusive instituições de ensino, onde o fluxo do público externo é muito alto e só através do seu publico interno integrado e fortalecido é que se torna possível o seu desenvolvimento. É preciso a integração de todos os setores para que as informações tomemo fluxo certo e atinjam os objetivos finais, pretendidos pela organização. Bueno (2002) defende a interação de todos os setores da organização e a capacitação dos funcionários para essas mudanças constantes.

Este trabalho iniciou-se pelo interesse e identificação no assuntoabordado e também pela sua importância, de ser um diferencial competitivo nas organizações. Muitas empresas, por não terem o conhecimento necessário do assunto, não investem e perdem uma excelente oportunidade de ter a sua comunicação elevada e fazer refletir isso para todos os seus clientes. A região do Cariri está em contínuo crescimento, essa pode ser a chave de sucesso de muitas, principalmente de Instituições de Ensino Superior, visto a crescente concorrência e evolução deste setor. Parti daí, nasceu o desejo de analisar como a comunicação pode melhor o 
desempenho de uma IES, com a seguinte problemática: Como o processo de comunicação organizacional pode melhorar o desempenho da IES?

A presente pesquisa tem como objetivo geral: Analisar a percepção dos colaboradores quanto ao processo de comunicação organizacional na IES.

Os objetivos específicos se dividiram em: 1) Descrever a forma de comunicação da IES; 2) Identificar os pontos positivos e negativos no atual processo de comunicação da empresa; 3 ) Identificar a percepção dos funcionários frente ao processo de comunicação organizacional da empresa.

\section{Referencial Teórico}

\section{Comunicação organizacional}

Para entender a comunicação empresarial, é preciso buscar o significado puro da palavra "comunicação", que segundo Penteado (1974) a palavra comunicar vem do latim communicaree etimologicamente significa trocar opiniões, tornar comum. E só há experiência quando todos os envolvidos participam e se entendem.

Gil(2001) conceitua comunicação como uma habilidade promovida pelos profissionais que atuam com funções gerenciais, principalmente para profissionais da área de recursos humanos, que precisão da oratória para se comunicar com uma ou mais pessoas.

Segundo Ferreira(1986), comunicação é como ato ou efeito de comunicar, processo que indivíduos trocamidéias, que resultem em um bom entendimento entre as pessoas.A comunicação é essa relação humana que se busca o censo comum e o entendimento final.

Como Chiavenato(2000) afirma, essa troca de informações, tornam as mensagens mais claras, o que faz da comunicação, processo fundamental entre indivíduos e organização.

Ainda nas definições de Chiavenato (2000), ele relata dois propósitos para a comunicação: a primeira é de repassar informações com clareza para que as pessoas possam realizar bem as tarefas, o que corresponde à habilidade de trabalhar.A segunda seria a de gerar a cooperação, motivação e satisfação das pessoas em seus cargos, promovendo a vontade de trabalhar. 


\section{A importância da comunicação organizacional e sua função estratégica}

Com a contínua evolução dos tempos e a competitividade cada vez mais acirrada das organizações, a valorização da comunicação é de grande importância para o desenvolvimento e sobrevivência das empresas.

De acordo com Ruggiero (2002), para potencializar a força humana, essencial para o crescimento da organização, é preciso que toda a equipe esteja bem informada, para a comunicação ser feita adequadamente.

Segundo Marchiori (2001), o comprometimento das pessoas só é possível, através das ações da empresa, que trará sentido para os funcionários, encontrado no processo de comunicação as justificativas para seu posicionamento. $O$ funcionário que sabe da sua importância do seu trabalho para o todo da organização, realizará suas tarefas com bem mais eficiência.

Já Bueno (2002), considera a importância da comunicação organizacional, na medida em que funcionários descontentes e mal informados, geram prejuízos para organização, uma vez que eles são os divulgadores de sua organização. Acabam sendo os "melhores porta-vozes" da instituição em que trabalham. A divulgação que é feita por eles, para os outros públicos, podem até não ser verídicas, mais se tornam fácil de acreditar, por está sendo transmitida por quem está vivendo lá dentro. Podemos concluir que os investimentos em comunicação interna se refletem no clima organizacional e também em marketing.

Para Argenti (2006), para que a estratégia de uma empresa obtenha sucesso, é preciso uma interligação entre a estratégia de comunicação e a estratégia geral da empresa. Um bom desempenho dessa comunicação reflete em um apoio a missão e visão da empresa. $\mathrm{O}$ autor acredita na forte ligação entre a comunicação empresarial eficiente e a própria organização. Nessa estratégia organizacional, estão incluídos:

- Determinar os objetivos: definição de objetivos claros, para que a comunicação gerencial seja bem sucedida, através de respostas obtidas pelo seu público.

- Decidir que recursos estão disponíveis: a comunicação, quase sempre depende de recursos, como dinheiro, recursos humanos e tempo. 
- Diagnosticar a reputação da organização: a reputação de uma empresa é fator crítico no desenvolvimento das estratégias, que é obtida com base na percepção do público-alvo da organização.

\title{
Comunicação interna
}

A missão básica da comunicação, para Rego (2002), é a manutenção de um clima positivo, em que sejam cumpridas todas as metas e o crescimento da organização seja contínuo e expandido suas linhas de produtos.

\begin{abstract}
A comunicação interna não pode ser algo isolado do composto da comunicação integrada e dos conjuntos das demais atividades da organização. Sua eficácia irá depender de um trabalho de equipe entre as áreas de comunicação e recursos humanos, a diretoria e todos os empregados envolvidos. (KUNSCH, 2003, p. 160)
\end{abstract}

Sendo assim, as informações se seguem um fluxo horizontal, no qual passam por todos os setores. Como Tavares (2009) expõe, a comunicação interna abrange: A comunicação entre departamentos, órgãos, unidades, etc.; a comunicação entre pessoas dos mesmos departamentos, órgãos, unidades, etc.; comunicação entre chefias; a comunicação entre funcionários e chefia direta, como supervisores e gerentes, e chefia indireta, como diretores e presidentes.

Analisando sua evolução, Kunsch (2006) afirma que as organizações mudaram totalmente o perfil, com novas preocupações, interesses e objetivos, antes a comunicação era vista como uma ultima palavras para investimento.

Atualmente o que se vê é a comunicação interna como uns dos únicos diferenciais no mercado atual, contra a concorrência. Até o conceito de marketing, dos 4 P's, pode ser igualado pela concorrência, comunicar-se bem é única vantagem competitiva, comenta Chinem (2006).

Segundo França (1999), o perfil do funcionário atual, compreende um profissional mais consciente, responsável e cuidadoso às cobranças. Eles estão mais conscientes da importância do seu trabalho para o funcionamento da empresa. 


\section{Ferramentas e canais da comunicação}

Para estabelecer contato com o público, a comunicação utiliza ferramentas e essas informações são passadas através de canais.

Tavares (2009), aponta como ferramentas de comunicação: Publicações internas; Memorando; Rádio interna; Circular; Relatório; Correio Eletrônico; Newsletters; Murais; Intranet; Entrevistas; Eventos(esportivos, sócias, culturais, congressos, palestra e workshops); Reuniões; Mala direta; Cartões; Cartas; Telefonemas.O autor ainda ressalta, que essas ferramentas mudam de acordo com evolução tecnológica.

Os canais de comunicação segundo França (1999) se dividem em quatro segmentos: auxiliar, oral, escrita e aproximativa. A auxiliar, considera os recursos tecnológicos existentes. Todos os recursos tecnológicos se encaixam na comunicação dirigida auxiliar. Na ferramenta oral, considera-se a mais rápida e eficaz ferramenta, na qual chega mais facilmente no público, mas sempre tendo em vista qual público-alvo se quer atingir, qual setor específico. A oral pode ser realizada através de telefonemas, reuniões, eventos, rádio interna e, principalmente conversa face a face. A autora considera na escrita, representada através de memorando, murais, cartas, cartões e publicações internas. A aproximativa é todo o contato físico, empresa com funcionário, englobando todos os veículos, como doação de bens e donativos, entrevistas, conversas, treinamentos, etc.

Para Dubrin (2001), as mensagens nas organizações se propagam em quatro direções, são elas:

Para baixo: informações da alta administração, para os subordinados. Envolvendo relatórios administrativos, manuais de política e procedimentos, jornais internos, relatórios de desempenho, etc.

Para cima: é a comunicação ascendente, dos subordinados para os superiores. Envolvendo conversas informais, reuniões grupais planejadas, relatórios, etc. Tem finalidade de informar e acessória na tomada de decisões. Para o desenvolvimento desse tipo de comunicação, as empresas criam programas como: Políticas de portas abertas, permite a qualquer empregado receber atenção; Programas de treinamentos, avalia aspectos da empresa; Programas de reclamações, todas as reclamações são enviadas para cima,como condição de trabalho, conflitos, assédios, reclamações com supervisores, etc. 
Comunicação Horizontal: comunicação de funcionários que estão no mesmo nível organizacional, no mesmo setor.

Comunicação Diagonal: este presente no dinamismo da empresa, no que diz respeito as tomadas de decisões, as informações fluem tanto nos níveis organizacionais mais altos ou mais baixos em diferentes departamentos.

Ainda considerando as explanações de Dubrin (2001), ele classifica de extrema importância a comunicação informal que são a rádio corredor, que é a principal fonte de transmissão de boatos, podendo até criar problemas para a organização e os encontros casuais, que não são programados, podendo acontecer com superiores e empregados, muitas vezes a alta direção utilizam desse canal sem preconceito, coletando informações que auxiliam na tomada de decisões.

\section{Apoios tecnológicos - comunicação eletrônica}

A transformação das organizações e suas atividades estão totalmente ligada a evolução tecnológica, ela possui um dos principais papéis na evolução dos negócios de comunicação social. Representa para alguns um verdadeiro choque cultural, no atrito do antigo com a desconhecida atualidade, comenta Nassar (1997).

Desde o surgimento da internet, as organizações começaram a contar com uma aliada forte para difundir a comunicação interna, de forma mais pratica, rápida e eficaz. A parti daí,foram criadasvarias ferramentas para auxiliar na comunicação, como a intranet, rede interna nas empresas que possibilita a comunicação entre todos os setores, também os portais corporativos, que possibilitam uma maior interação no ambiente organizacional e a vídeoconferência.

\section{Diferenças dentre comunicação interna e endomarketing}

Embora se confunda muito comunicação interna com endomarketing por tratarem do público interno, são assuntos distintos, com definições e aplicações diferentes. 
Para Brum (1998), o endomarketing tem uma visão mercadológica nos seus clientes internos. Tem como ideal tornar o ambiente interno mais agradável possível, para que seus clientes internos possam ter mais rendimento nas suas atividades. A definição da palavra endomarketing significa pra dentro, ou seja marketing interno.

Segundo Tavares (2009), os dois conceitos não podem ser visto separadamente, andam sempre juntos, uma vez que o endomarketing gera fidelidade do público interno e a comunicação interna gera lealdade.

\section{Metodologia}

Segundo Barcelos e Miranda (2007),um artigo científico, busca resultados e informações, através de pesquisa, que seja transmitido, de uma maneira transparente e breve.

Seguindo essa direção, o trabalho foi desenvolvido, quanto ao método, por uma revisão bibliográfica, que Mattar (2001), classifica como uma das formas de pesquisa exploratórias. A pesquisa exploratória tende a aumentar o conhecimento do pesquisador, sobre o problema em questão.

A pesquisa foi constituída quanto à forma de abordagem, quantitativa, que, Tanaka (2001), afirma ter como característica, permitir uma abordagem focada e estruturada, usando de dados quantitativos e obtenção de respostas estruturadas.

Quanto aos objetivos da pesquisa, se tratou de uma pesquisa descritiva. Rúdio (2007), afirma que na pesquisa descritiva, o pesquisador não modifica neminterfere nos resultados, mas procura conhecer e interpretar a realidade.

A amostra é composta pelos os colaboradores da IES, e se caracteriza como nãoprobabilística, que para Mattar (1996), é aquela que para que a amostra seja composta é necessária ao menos em parte do julgamento do pesquisador. O tamanho da amostra constituiuse por um quadro de 46 colaboradores da empresa em questão. Foi realizado com 4 colaboradores de cada setor, os setores são: Apoio (segurança), Apoio (limpeza), Apoio (acadêmico), Biblioteca, Corpo Docente Curso de Administração, Curso de Direito, Curso de Sistema de Informação, Multimídia, NPJ (Núcleo de Prática Jurídica), Recepção e, Secretaria.

O instrumento utilizado na coleta de dados foi um questionário fechado, dividido em 09(nove) questões sobre a comunicação da IES, baseado nas principais ferramentas de 
comunicação, referenciando Tavares (2009), nos canais de comunicação, seguindo os pensamentos de França (1999) e em relação a propagação das mensagens, considerando as explanações deDubrin (2001). Também foi elaborado um questionário sócio demográfico, dividindo-se em 07(sete) questões. Onde foi realizado na própria IES, no período de 23 a 27 de maio de 2011.

\section{Apresentação e Análise dos Resultados}

$\mathrm{Na}$ sequência, são apresentados e analisados os resultados obtidos. Inicia-se com a apresentação do perfil dos respondentes e posteriormente as questões relativas da comunicação organizacional. Onde todos os setores da IES foram respondentes do questionário.

Assim, no que se refere à faixa etária, os dados mostram que são predominantes os colaboradores, que tem entre 21 a 30 anos, totalizando 58,70\% da amostra. Seguidos dos que possuem de 31 a 45 anos (32,61\%), depois os de até 20 anos (8,70\%). Quanto ao sexo dos respondentes, houve uma pequena diferença, onde o sexo masculino representa $52,17 \%$ e o feminino, 47,73\%. Quando foi perguntado a respeito do estado civil, as respostas se dividiram. A maioria de solteiros, com $56,52 \%$ e casados com $43,48 \%$.

Quanto a escolaridade verificou-se que fica bem dividido os percentuais como apresentado no gráfico abaixo:

Gráfico 1 - Escolaridade.

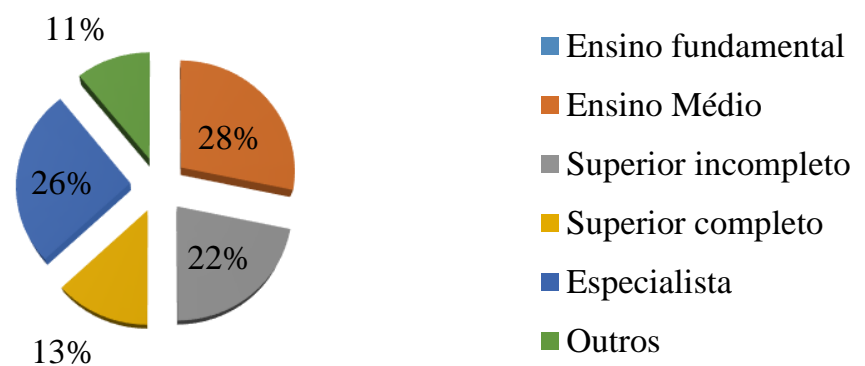

Fonte: o autor

Dados da pesquisa 
Quanto a faixa salarial, apresentou-se uma pequena diferença, de $5,00 \%$, entre a faixa de até 2 salários mínimos e entre 10 a 20 salários.

Gráfico 2 - Faixa salarial familiar.

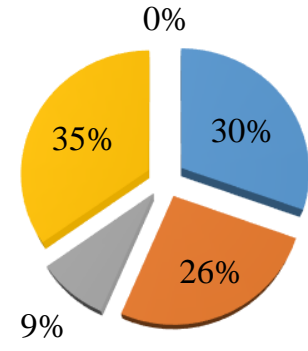

- Até 2 salários mínimos

Entre 2 e 4 salários

mínimos

Entre 4 e 10 salários

mínimos

Entre 10 e 20 salários

mínimos

Fonte: o autor

Dados da pesquisa

Quanto ao tempo de empresa, verificou-se que a maioria fica nas faixas correspondentes a "de um ano a dois anos" e "de dois anos a 3 anos" perfazendo um total de $61 \%$. Obviamente que isso deve-se ao início das atividades, dado que a IES tem apenas pouco mais de 5 anos de existência.

Gráfico 3 - Tempo de empresa.

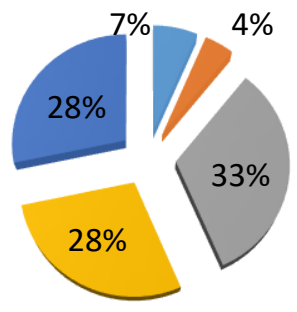

$$
\begin{aligned}
& \square \text { Até } 6 \text { meses } \\
& \square \text { De } 6 \text { meses a } 1 \text { ano } \\
& \square \text { De } 1 \text { ano a } 2 \text { anos } \\
& \text { De } 2 \text { anos a } 3 \text { anos } \\
& \square \text { Acima de } 3 \text { anos }
\end{aligned}
$$

Fonte: o autor

Dados da pesquisa

Todos os setores foram pesquisados, sendo assim, em percentuais sobre o total, ficaram divididos em: Apoio (Segurança) com 8,70\%; Apoio (Limpeza) com 8,70\%;Apoio Acadêmico 
com 8,70\%; Biblioteca com 8,70\%; Corpo Docente com 8,70\%;Curso de Administração com 8,70\%, Curso de Direito com 8,70\%; Curso de Sistema de Informação com 8,70\%; Multimídia com 8,70\%; NPJ com 8,70\%; Recepção com 4,35\% e Secretaria com 8,70\%; do total de respondentes.

Sobre as ferramentas de comunicação, baseadas em Tavares (2009), que os respondentes têm conhecimento que a instituição utiliza, verificou-se que a maioria conhece bem em primeiro lugar a ferramenta 6 que trata-se do correio eletrônico, em segundo lugar a ferramenta 11 que trata-se eventos (esportivos, sociais, culturais, palestras) e em terceiro lugar empatadas as ferramentas 12 e 16 que são, respectivamente, reuniões e telefonemas. Verificou-se que os que são menos conhecidos são a ferramenta 4 que trata-se da circular interna (algo muito importante para uma organização) bem como as ferramentas 7 e 9, respectivamente as que tratam de Boletins informativos ou Newslatters e Intranet (duas importantes ferramentas muito utilizadas nas organizações atuais). As outras ferramentas, que não foram comentadas, correspondem a: 1 - publicações internas, 2 - memorando, 3 - rádio interna, 5 - relatório, 8 - murais, 10 entrevistas, 13 - mala direta, 14 - cartões e 15 - cartas.

Gráfico 4 -Ferramentas de comunicação utilizadas.

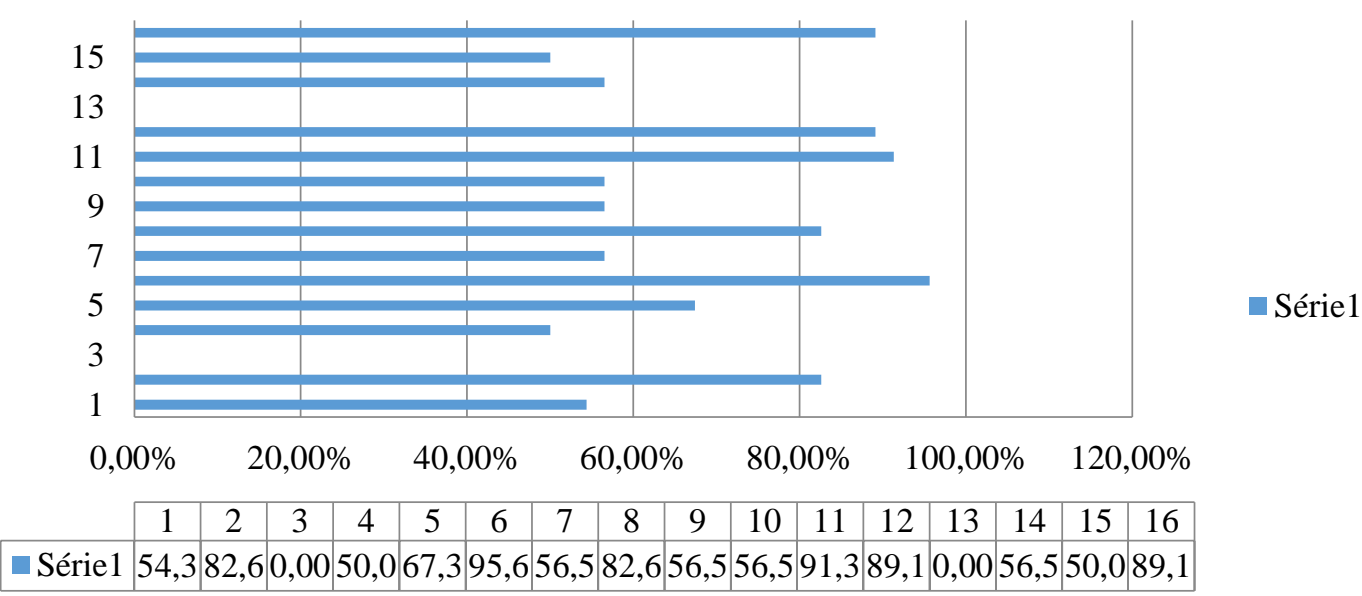

Fonte: o autor

Dados da pesquisa

Depois de identificar as ferramentas que os colaboradores têm conhecimento que a faculdade utiliza, pretende-se descobrir o grau de importância de cada ferramenta, apresentado abaixo onde se pôde observar que o mais importante foia ferramenta de publicações internas, 
nas quais não são de muito conhecimento por parte dos colaboradores de acordo com o gráfico 4 exposto acima em que esta ferramenta corresponde a de número 4 . Outra ferramenta de muita importância foi a de telefonemas e memorandos.

Gráfico 5 - Grau de importância das ferramentas.

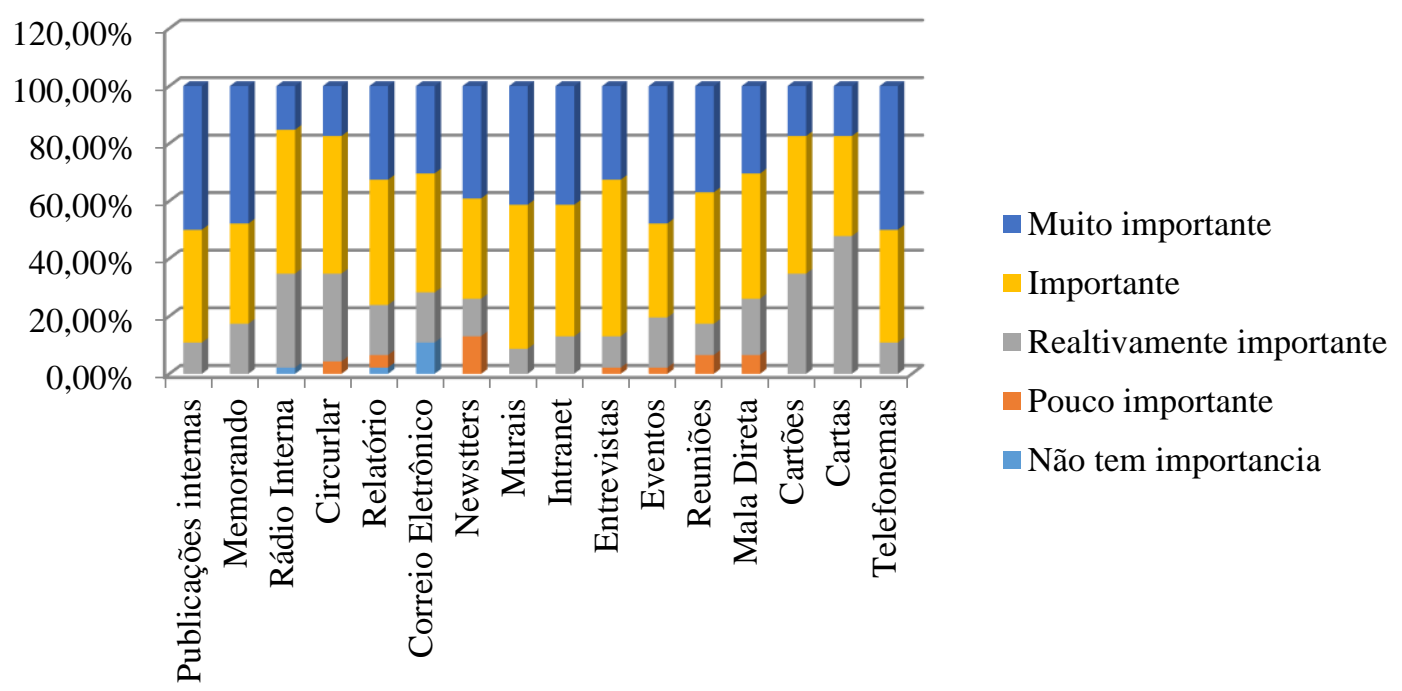

Fonte: o autor

Dados da pesquisa

Em relação aos canais de comunicaçãoque segundo França (1999)dividem-se em quatro segmentos que são: auxiliar, oral, escrita e aproximativa, observa-se o seguinte:

1-Concordo totalmente, 2-Concordo parcialmente, 3-Nem concordo nem discordo, 4Discordo parcialmente e 5 - Discordo totalmente.

Quadro - 1 Canais de comunicação segundo França(1999)

\section{Perguntas referentes aos segmentos segundo Franca (1999)}

Os recursos tecnológicos estão sendo usados de maneira eficiente no processo de comunicação da faculdade?

A comunicação oral (telefonemas, reuniões, eventos, conversa face a face) está sendo feita de maneira eficiente no processo de comunicação da faculdade?

A comunicação escrita (memorando, cartas, murais, publicações internas) está sendo feita de maneira eficiente e eficaz no processo de comunicação da faculdade?

\begin{tabular}{|c|c|c|c|c|c|}
\hline 1 & 2 & 3 & 4 & 5 \\
\hline 25 & 15 & 4 & 2 & 0 \\
\hline 23 & 17 & 1 & 5 & 0 \\
\hline 17 & 22 & 4 & 3 & 0 \\
\hline
\end{tabular}


A comunicação aproximativa (conversas, entrevistas, treinamentos) está sendo feita de maneira eficiente e eficaz no processo de comunicação da faculdade?

Fonte: o autor

Dados da pesquisa

Percebe-se com isso, em relação aos recursos tecnológicos, que a maioria com 54\% concordam totalmente que os recursos tecnológicos estão sendo utilizados de maneira eficiente, porém boa parte dos respondentes, ou seja, $32 \%$ concordam parcialmente.

Sobre a comunicação oral, $50 \%$ dos respondentes concordam totalmente e $36 \%$ concordam parcialmente.Em relação àcomunicação escrita, aqui já muda um pouco onde a maioria com $47 \%$ dos respondentes concordam parcialmente e $36 \%$ são os que concordam totalmente.Sobre a comunicação aproximativa, $45 \%$ concordam totalmente e $32 \%$ concordam parcialmente.

Quanto às propagações das direções das mensagens segundo Dubrin (2001), apresentase da seguinte forma:

Quadro 2 - Propagações das direções das mensagens segundo Dubrin (2001).

\begin{tabular}{|l|l|l|l|l|l|}
\hline \multicolumn{1}{|c|}{ Propagações das direções das mensagens segundo Dubrin (2001). } & $\mathbf{1}$ & $\mathbf{2}$ & $\mathbf{3}$ & $\mathbf{4}$ & $\mathbf{5}$ \\
\hline $\begin{array}{l}\text { O processo de comunicação da alta administração para os subordinados é } \\
\text { realizado de maneira clara e é eficiente e eficaz no processo de comunicação } \\
\text { da faculdade. }\end{array}$ & $\mathbf{1 3}$ & $\mathbf{1 8}$ & $\mathbf{8}$ & $\mathbf{1}$ & $\mathbf{5}$ \\
\hline $\begin{array}{l}\text { O processo de comunicação ascendente, ou seja, dos subordinados para os } \\
\text { superiores é realizado de maneira clara e é eficiente e eficaz no processo de } \\
\text { comunicação da faculdade. }\end{array}$ & $\mathbf{1 9}$ & $\mathbf{1 5}$ & $\mathbf{9}$ & $\mathbf{3}$ & $\mathbf{0}$ \\
\hline $\begin{array}{l}\text { O processo de comunicação entre funcionários que estão no mesmo nível } \\
\text { organizacional é realizado de maneira clara e é eficiente e eficaz no processo } \\
\text { de comunicação da faculdade. }\end{array}$ & $\mathbf{1 7}$ & $\mathbf{2 0}$ & $\mathbf{9}$ & $\mathbf{0}$ & $\mathbf{0}$ \\
\hline $\begin{array}{l}\text { O processo de comunicação entre os diversos níveis e setores da faculdade é } \\
\text { realizado de maneira clara e é eficiente e eficaz no processo de comunicação } \\
\text { da faculdade. }\end{array}$ & $\mathbf{1 4}$ & $\mathbf{1 9}$ & $\mathbf{8}$ & $\mathbf{4}$ & $\mathbf{1}$ \\
\hline
\end{tabular}

Fonte: o autor

Dados da pesquisa

Com as respostas pôde-se observar que boa parte dos respondentes, ou seja, 39\% concordam parcialmente e não totalmente quanto a comunicação da alta administração para os subordinados. Em relação ao processo de comunicação ascendente, $41 \%$ concordam totalmente. Chamou à atenção a comunicação entre funcionários do mesmo nível organizacional, onde a maioria, ou seja, $43 \%$ concordam parcialmente. E por último entre os diversos níveis - chamada 
de comunicação diagonal - a maioria dos respondentes com $41 \%$ concordam parcialmente. $\mathrm{E}$ em todas as perguntas, em torno de $19 \%$ dos respondentes nem concordam nem discordam.

Em relação a pergunta sobre o que mais é acessado por parte dos colaboradores para obter informações, foi observado que, em primeiro lugar, é acessado a ferramenta "Newslatters", porém aqui houve uma controvérsia dado que na pergunta sobre conhecimento sobre meios de comunicação da organização, os respondentes mostraram não conhecer bem essa ferramenta, ficando como um dos menos conhecidos. Em segundo lugar ficou a ferramenta "murais" e em terceiro lugar a ferramenta "reuniões".

Verifica-se que as ferramentas "e-mail" e "intranet" não são muito acessados indo de encontro com o quadro 1 que informou que $32 \%$ concordam parcialmente sobre a efetividade dos recursos tecnológicos para o processo de comunicação.

Sobre a avaliação a respeito da comunicação interna da faculdade, observa-se o gráfico abaixo.

Gráfico 4 - Avaliação da comunicação interna da IES.

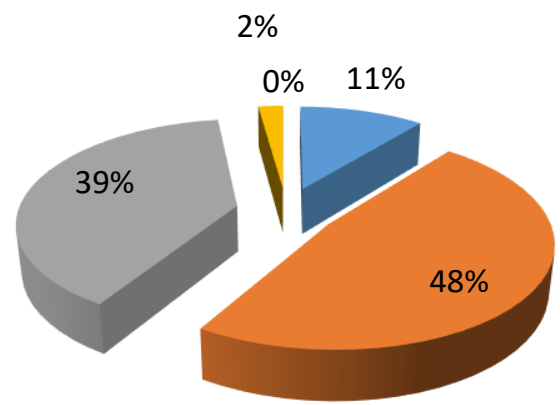

$$
\begin{aligned}
& \text { Exelente } \\
& \text { Bom } \\
& \text { Regular } \\
& \text { Ruim } \\
& \text { Péssima }
\end{aligned}
$$

Fonte: o autor

Dados da pesquisa

Observa-se que 48\% dos respondentes acham a comunicação interna da IES "boa" e $39 \%$ dos respondentes acham "regular". Se foram somados os respondentes regular e ruim deu uma fatia de $41 \%$ mostrando que é necessário um revisão do processo de comunicação da faculdade.

Em relação a ações que os colaboradores sugerem para melhoria, segue o quadro abaixo: 
Quadro 3 - Ações sugeridas pelos colaboradores.

\begin{tabular}{|l|c|}
\hline Aumentar/ melhorar os recursos tecnológicos ou aproveitar mais os recursos tecnológicos. & $\mathbf{3 9 , 1 3 \%}$ \\
\hline Aumentar/ melhorar a comunicação oral (telefonemas, reuniões, conversas face a face) & $\mathbf{3 2 , 6 1 \%}$ \\
\hline Aumentar/ melhorar a comunicação escrita (murais, publicações internas) & $\mathbf{4 , 3 5 \%}$ \\
\hline Aumentar/ melhorar a aproximação uns com os outros (conversas, entrevistas, treinamentos) & $\mathbf{2 3 , 9 1 \%}$ \\
\hline
\end{tabular}

Fonte: o autor

Dados da pesquisa

Isso mostra que deve ser melhorado ou aproveitado melhor os recursos tecnológicos bem como haver mais comunicação oral (reuniões e conversas face a face).

Em relação a importância da comunicação organizacional para os colaboradores, segue quadro abaixo:

Quadro 4 - Importância da comunicação organizacional

\begin{tabular}{|l|c|}
\hline A comunicação é fundamental nas relações interpessoais & $\mathbf{2 1 , 7 4 \%}$ \\
\hline A comunicação é fundamental no bom andamento dos processos da faculdade & $\mathbf{2 6 , 0 9 \%}$ \\
\hline A comunicação é fundamental para o bom atendimento aos alunos e professores & $\mathbf{4 , 3 5 \%}$ \\
\hline A comunicação é fundamental para a estratégia da organização & $\mathbf{4 7 , 8 3 \%}$ \\
\hline
\end{tabular}

Fonte: o autor

Dados da pesquisa

Observa-se com isso que 47,83\% dos respondentes acham que a comunicação é fundamental para a estratégia da organização.

Sobre a última pergunta, a mesma livre onde foi questionada qual a maior dificuldade em se comunicar com o setor ou demais setores da faculdade observou-se que a falta de diálogo a limitação tecnológica, o retorno de solicitações e a falta de feedback são os mais encontrados. Isso mostra que é necessário uma revisão do processo de comunicação para que a estratégia da organização seja realizada de forma eficaz. 


\section{Considerações Finais}

Com o crescimento acelerado das organizações de todos os setores, a comunicação organizacional, se tornou ferramenta essencial para a sobrevivência e sucesso das empresas. Este fato faz com que o administrador utilize de todos os instrumentos necessários para manter o fluxo de informações eficaz e manter a organização competitiva.

Nesse sentido, a comunicação organizacional, se torna um importante diferencial para a empresa, onde busca agregar esforços de toda a organização, tornando os colaboradores parceiros na busca para alcançar os objetivos.

Com base no que foi exposto até aqui, buscou-se analisar justamente a percepção dos colaboradores, que são o principal recurso para uma comunicação integrada. Onde, obtiveramse respostas para todos os objetivos específicos. Na forma de comunicação da IES, os colaboradores apontaram as ferramentas que têm mais conhecimento: correio eletrônico, reuniões e telefonemas.

Foi verificado como ponto positivo na comunicação organizacional, que os recursos tecnológicos estão sendo utilizados de maneira eficiente pela IES, visto que pouco mais da metade dos respondentes concordam totalmente. Mesmo com a maioria concordando, foi também apontado como melhoria para o processo da comunicação o aumento dos recursos tecnológico, ou um melhor aproveitamento do mesmo. Demonstra que os recursos tecnológicos ainda podem ser mais aproveitados pela IES.

Com analise dos dados também foi apurado, a percepção dos colaboradores a comunicação interna da IES. A maioria respondeu que está "boa", mas, se somaram os que responderam "regular" e "ruim", chega a um percentual muito próximo do "boa". Tornando necessária uma revisão na estratégia de comunicação. A maioria dos colaboradores também aponta a comunicação como fundamental para a estratégia da organização.

Sendo assim, em consequência da importância do tema pesquisado e em virtude dos resultados obtidos, esse ensaio aponta que a organização pesquisada, utilize de maneira mais eficaz suas ferramentas de comunicação e que as estratégias de comunicação sejam reavaliadas. Somente assim, a organização poderá aproveitar o potencial desse importante diferencial competitivo, e tê-lo como aliado para integração o alcance dos objetivos. 
Id on Line Revista Multidisciplinar e de Psicoloqia

Id on Line Multidisciplinary and Psycology Journal

\section{Referências}

ARGENTI, Paul A. Comunicação Empresarial: a construção da identidade, imagem e reputação. Rio de Janeiro: Elsevier, 2006.

BARCELLOS, Inêz; Miranda, Cristina. Manual para elaboração e apresentação de trabalhos científicos. Campos dos Goytacazes, 2007.

BUENO, Wilson da Costa. Comunicação Empresarial: Teoria e Prática. $1^{\circ}$ Ed., 2002.

BRUM, Analisa de Medeiros. Endomarketing: Estratégias de comunicação interna para empresas que buscam a qualidade e a competitividade. Porto Alegre: Ortis, 1998.

CHIAVENATTO, Idalberto. Introdução à Teoria Geral da Administração. $6^{\circ}$ Ed., Rio de Janeiro: Campus, 2000.

CHINEM, Rivaldo. Comunicação empresarial: teoria e o dia a dia das assessoriasde comunicação. São Paulo, SP: Horizonte, 2006.

DUBRIN, Andrew J. Princípios da Administração. Tradução Roberto Minadeo. $4^{\circ}$ Ed. Rio de Janeiro: LCT, 2001.

FERREIRA, A. B. de H. Novo dicionário de língua portuguesa. $2^{\circ}$ Ed. Rio de Janeiro: Nova Fronteira, 1986.

FRANÇA, Fábio; MELO, Waltemir de; FREITAS, Sidnéia Gomes; MESTIERI, Carlos Eduardo. Obtendo Resultados com Relações Públicas. $1^{\circ}$ Ed. São Paulo, SP: Pioneira, 1999.

GIL, Antônio Carlos. Gestão de pessoas: enfoque nos papéis profissionais. São Paulo: Atlas, 2001.

KUNSCH, Margarida Maria Krohling. Planeijamento de Relações Públicas na Comunicação Integrada. $4^{\circ}$ Ed. São Paulo, SP: Summus, 2003.

, Margarida Maria Krohling ( Organizadora). Obtendo resultados com Relações Públicas: como utilizar adequadamente as Relações Públicas em benefício das organizações e da sociedade em geral. $2^{\circ}$ Ed. Ver. São Paulo, SP: Pioneira Thomson Learning, 2006.

MARCHIORI, Marlene Regina. Cultura organizacional: conhecimento estratégico no relacionamento e na comunicação com os empregados, 2001.Tese (Doutorado em Ciências da Comunicação) - Universidade de São Paulo, São Paulo.

MATTAR, FauzeNajib:Pesquisa de Marketing.São Paulo: Atlas, 2001.

Fauze Najib:Pesquisa de Marketing. São Paulo: Atlas, 1996. 
MATOS, Gustavo Gomes. A cultura do diálogo: Uma estratégia de comunicação nas empresas. Rio de Janeiro. Elsevier, 2006.

NASSAR, Paulo. Obtendo resultados em Relações Públicas. São Paulo: Pioneira, 1997.

PENTEADO, José Roberto Whitaker. A técnica da comunicação humana. 4. ed. São Paulo: Pioneira, 1974.

REGO, Francisco Gaudêncio Torquato do. Tratado de Comunicação Organizacional e Política. São Paulo: Pioneira, 2002.

RÚDIO, Franz Victor. Introdução ao projeto de pesquisa científica. $34^{\circ}$. ed.Petrópolis: Vozes, 2007.

RUGGIERO, Alberto Pirró. Qualidade da comunicação interna. 08 out. 2002. Disponível em: http://www.rh.com.br. [acesso em 07.maio.2011]

TAVARES, Maurício. Comunicação empresarial e planos de comunicação: integrando teoria e prática. $2^{\circ}$ Ed., ver. Ampl São Paulo, SP: Atlas, 2009.

TANAKA, Oswaldo Y.; Melo, Cristina. Avaliação de Programas de Saúde do Adolescenteum modo defazer. Capitulo IV. São Paulo : Edusp, 2001.

Como citar este artigo (Formato ABNT):

LIMACHI, Islly G. T.; ROCHA, Paloma de S. A Importância da Comunicação Organizacional na Atuação das Equipes em uma IES na Cidade de Juazeiro do Norte-CE.. Id on Line Revista Multidisciplinar e de Psicologia, Abril de 2017, vol.11, n.35, p.137-154. ISSN: 1981-1179.

Recebido: 04.04.2017

Aceito: 19.04.2017 